\title{
The Mode of Action of Analgesic Drugs in Adjuvant Arthritic Rats as an Experimental Model of Chronic Inflammatory Pain: Possible Central Analgesic Action of Acidic Nonsteroidal Antiinflammatory Drugs
}

\author{
Shigeru OKUYAMA and Hironaka AIHARA \\ Research Center, Taisho Pharmaceutical Co., Ltd., \\ Yoshino-cho 1-403, Ohmiya, Saitama 330, Japan \\ Accepted February 16, 1984
}

\begin{abstract}
The analgesic activities of intracerebroventricular (icv) administrations of some analgesic drugs, morphine, indomethacin, diclofenac, aminopyrine and acetaminophen, were studied in comparison with those of systemic administrations in normal rats and adjuvant arthritic rats. A method for the measurement of analgesic potency in normal rats and adjuvant arthritic rats were developed using the vocalization response as an indicator of pain resulting from electrical stimulation. The systemic and/or icv administered indomethacin and diclofenac produced much more potent analgesic action in adjuvant arthritic rats than in normal rats. Morphine, aminopyrine and acetaminophen given by the two routes showed roughly the same analgesic effect in both types of rats. Simultaneous systemic and icv administrations of indomethacin and/or diclofenac showed an additive effect in normal rats, but showed a synergistic effect rather than a simple additive effect in adjuvant arthritic rats. Those of morphine, aminopyrine and acetaminophen showed only additive effects in both types, except for that of aminopyrine in normal rats. Moreover, the brain and serum levels of non-metabolized indomethacin and aminopyrine were measured after the normal and adjuvant arthritic rats were systemically given these drugs. In adjuvant arthritic rats, the icv effective dose of indomethacin was the same as the brain level of non-metabolized indomethacin after the systemic administration. The effective dose of indomethacin administered icv in the normal rats was 17 times higher than the brain level of non-metabolized indomethacin administered systemically. The icv effective dose of aminopyrine was 4-4.5 times higher than the level of the brain concentration of non-metabolized drug in both types of rats. It was suggested that acidic nonsteroidal antiinflammatory drugs (NSAIDs) such as indomethacin and diclofenac specifically inhibit inflammatory pain, and the pain-relieving properties of acidic NSAIDs may be related to the central as well as the peripheral site of action.
\end{abstract}

In general, the differences between the two types of analgesic drugs are recognized depending upon their site of action, the narcotic analgesic drugs block the central pathway of pain, while NSAIDs act as analgesic drugs peripherally by blocking the generation at the chemonociceptors for pain.

Guzman et al. and Lim et al. demonstrated that the analgesic action of NSAIDs is due to the blockade of pain impulse generation at the peripheral chemonociceptors $(1-3)$. This hypothesis has been supported by recent findings: prostaglandins found in inflammatory exudates sensitize the pain receptors to mechanical or chemical stimulation, and the synthesis of the prostaglandins is inhibited in vivo by NSAIDs (4-6). On the other hand, Ferreira et al. (7) demonstrated a significant analgesic action in rats with 
carrageenin-induced hyperalgesia by the systemic, local and central administration of NSAIDs. The in vivo effects of orally adminstered NSAIDs on prostaglandin $E$ and $F$ were determined in the brain tissue of normal rats. The suppression of prostaglandin biosynthesis in the brain was exhibited by acidic NSAIDs, but not by nonacidic NSAIDs $(8,9)$. Moreover, Chen and Chapman (10) reported that aspirin was shown to decrease the brain-evoked potentials produced by electric shocks supplied to the tooth.

In our previous studies (11), a method for the evaluation of analgesic drugs in normal rats and in rats with hyperalgesia induced by adjuvant were reported. Adjuvant arthritic rats were used as models for chronic inflammatory pain. We have observed that adjuvant arthritic rats exhibit a lower pain threshold than normal rats. Acidic NSAIDs showed a much more potent analgesic action in adjuvant arthritic rats than in normal rats. In contrast, nonacidic NSAIDs, narcotic analgesic drugs and narcotic agonist/ antagonist type analgesic drugs had roughly the same analgesic effect in both types of rats.

Hereafter, it is thought that adjuvant arthritic rats would be important as models to explore the mode of the analgesic action of acidic NSAIDs. Moreover, it is seem that site of action of acidic NSAIDs is not only peripheral, but also central.

In the present study, the analgesic effects of the icv administrations of some analgesic drugs were studied by comparing them with those of systemic administrations in normal and adjuvant arthritic rats. In addition, the brain and serum levels of non-metabolized indomethacin and aminopyrine were measured after normal and adjuvant arthritic rats were systemically administered.

\section{Materials and Methods}

\section{Animals}

Male Sprague-Dawly rats weighing 140$160 \mathrm{~g}$ at the time of the Mycobacterium butyricum (adjuvant, Difco Laboratories, Detroit, MI) injection were housed in an air-conditioned room at $22 \pm 1^{\circ} \mathrm{C}$ with a $12 \mathrm{hr}$ light-dark schedule (light on at 7:00). Food and water were given ad libitum during the experimental period.

Rats were injected intradermally at the base of the tail with $0.1 \mathrm{ml}$ of a paraffin oil suspension of heat-killed adjuvant $(0.5 \mathrm{mg})$. The effects of drugs were determined from day 15 to day 20 after the adjuvant injection since the pain threshold for hyperalgesia was stable at this time. The normal rats used were the same age as the adjuvant arthritic rats.

\section{Measurement of analgesic potency}

The rats were placed in a test chamber made of acrylic resin (inside dimensions: $30 \times 30 \times 35 \mathrm{~cm}$ ). The floor grid was prepared for electrical stimulation, and a nondirectional microphone with high impedance $(10,000 \Omega)$ was attached to the ceiling. For electrical stimulations, a cathode was connected to the floor grid and an anode was connected to the dorsal skin of the rat. The rats were subjected to rectangular wave pulses generated by a stimulator (SEN-7301. Nihon Kohden). The animals received electrical stimulation at a frequency of $10 \mathrm{~Hz}$ with a pulse duration of $5 \mathrm{msec}$. The intensity of electrical stimulation was gradually stepped up $(0.1$ to $0.25 \mathrm{~mA})$. The vocalization response in adjuvant arthritic and normal rats increased in parallel with intensity of electrical stimulation and reached a plateau at 0.6 to $2.6 \mathrm{~mA}(\mathrm{~m}=1.6 \pm 0.1 \mathrm{~mA})$ and 4.5 to $5.5 \mathrm{~mA}$ $(m=5.1 \pm 0.2 \mathrm{~mA})$, respectively. The animals were stimulated by submaximum intensity (about $80 \%$ of maximum intensity): Adjuvant arthritic rats and normal rats were stimulated between 0.5 and $1.5 \mathrm{~mA}(\mathrm{~m}=1,2 \pm 0.1 \mathrm{~mA})$ and between 3.5 and $5.5 \mathrm{~mA}(\mathrm{~m}=3.9 \pm 0.2$ $m A$ ), respectively. About $20 \%$ of the animals showed running in the test chamber, biting of the floor grid or jumping during the electrical stimulation, which could interfere with measurement of the vocalization response. Such animals were avoided in our pharmacological investigation. Under these stimulation conditions, 5 successive stimulations for $5 \mathrm{sec}$ were applied at intervals of $15 \mathrm{sec}$ every $30 \mathrm{~min}$, producing reproducible vocalization responses up to $8 \mathrm{hr}$.

When the rats were stimulated, the vocalization responses were detected with a microphone and relayed through a low-cut filter $(530 \mathrm{~Hz})$, biophysical amplifier (AB$620 \mathrm{G}$, Nihon Kohden) and an integrator (EI- 
600 G, Nihon Kohden) for an inkwriting oscilloscope (WT-645 G, Nihon Kohden).

\section{Icv administration}

ICV administrations were made according to a modification of the technique described by Correa and Graeff (12). The rats were anesthetized with sodium pentobarbital, and the head was held horizontally by a stereotaxic apparatus. The locus for insertion of a stainless guide cannula (outer diameter: 0.7 $\mathrm{mm}$ ) was determined according to the stereotaxic atlas of Pellegrino and Cushman (13). A guide cannula was implanted into the left ventricle (A: 2.8, L: 1.5, $\mathrm{H}:+0.8$ ). Each drug was dissolved in $10 \mu \mathrm{l}$ of the vehicle and injected at a rate of $10 \mu \mathrm{g} / \mathrm{min}$ through an intercannula made of stainless steel (outer diameter: $0.3 \mathrm{~mm}$ ). Each animal was allowed one week to recover after surgery.

4. Determination of non-metabolized indomethacin and aminopyrine in the brain and serum

Adjuvant arthritic and normal rats were used. Each group consisted of 6 animals. The blood samples were obtained by venesectioning of the femoral vein and/or artery under ether, and the animals were decapitated and the brain was quickly removed. The serum was obtained from blood by centrifugation at $3000 \mathrm{rpm}$ for $15 \mathrm{~min}$. The quantitative determinations of these samples were performed by GC/MS (Shimadzu-LKB 9000) computerized mass fragmentography.

\section{Quantitation of indomethacin}

Serum: Rat serum $(1 \mathrm{ml})$ was extracted with $3 \mathrm{ml}$ of ethyl acetate in the presence of $40 \mu \mathrm{g}$ of indomethacin (d-3) as the internal standard. The resultant organic phase $(1.5 \mathrm{ml})$ was evaporated to dryness by reduced pressure. The residue was dissolved in $1 \mathrm{ml}$ of diazomethane and allowed to stand at room temperature for $30 \mathrm{~min}$. After evaporation of the solvent, the residue was dissolved in $200 \mu$ of ethyl acetate and applied to GC/ MS.

Brain: The whole brain of the rats was homogenized in $13 \mathrm{ml}$ of acetone. The homogenates were centrifuged at $3000 \mathrm{rpm}$ for $15 \mathrm{~min}$, and the supernatants were evaporated to dryness by reduced pressure. The residue was dissolved with $3 \mathrm{ml}$ of acetic acid $(\mathrm{pH} \mathrm{4})$ and extracted with $3 \mathrm{ml}$ of ethyl acetate. The resultant organic phase was evaporated and dissolved in $100 \mu \mathrm{l}$ of ethyl acetate containing $2 \mu \mathrm{g}$ of indomethacin as the internal standard, then applied to silica gel TLC plates. The chromatograms were developed in dichlormethane/acetic $\mathrm{acid} / \mathrm{methanol}(20: 1: 0.5, \mathrm{~V} / \mathrm{V} / \mathrm{V})$. The internal standard was located using a UV-lamp. scraped and extracted with acetone/ chloroform $(1: 1, V / V)$. The extract was evaporated and dissolved in $1 \mathrm{ml}$ of diazomethane. These solvents were allowed to stand for $30 \mathrm{~min}$ at room temperature. After evaporation of the solvent, the residue was dissolved in $200 \mu l$ of ethyl acetate and applied to GC/MS.

\section{Quantitation of aminopyrine}

Serum: Rat serum $(1 \mathrm{ml})$ was extracted with $2 \mathrm{ml}$ of acetone and $100 \mu \mathrm{g}$ of ethanol in the presence of $4 \mu \mathrm{g}$ aminopyrine (d-6) as the internal standard. The solvent was mixed and was centrifuged at $3000 \mathrm{rpm}$ for $15 \mathrm{~min}$. The resultant organic phase $(1 \mathrm{ml})$ was concentrated to $0.5 \mathrm{ml}$ by a $\mathrm{N}_{2}$ stream and applied to a GC/MS.

Brain: The whole brain of rats was homogenized in $6 \mathrm{ml}$ of acetone and $100 \mu \mathrm{l}$ of ethanol in the presence of $10 \mu \mathrm{g}$ of aminopyrine as the internal standard. The homogenates were centrifuged at $3000 \mathrm{rpm}$ for 15 min. The resultant organic phase $(5.5 \mathrm{ml})$ was evaporated and dissolved in $3 \mathrm{ml}$ of $\mathrm{H}_{2} \mathrm{O}$ and $3 \mathrm{ml}$ of benzene. The resultant organic phase $(1 \mathrm{ml})$ was concentrated to $0.5 \mathrm{ml}$ by a $\mathrm{N}_{2}$ stream and applied to $\mathrm{GC} / \mathrm{MS}$.

\section{Data analysis}

To evaluate the effects of NSAIDs in adjuvant arthritic rats, 5 successive stimulations of $15 \mathrm{sec}$ intervals were applied every $30 \mathrm{~min}$ for $5 \mathrm{hr}$. Adjuvant arthritic rats given the narcotic analgesic drugs received stimulation every $30 \mathrm{~min}$ for $3 \mathrm{hr}$. Stimulations were applied to normal rats every $30 \mathrm{~min}$ for $2 \mathrm{hr}$ for all the drugs.

The average vocalization of each measurement was calculated by the mean values of 5 vocalization areas. The degree of vocalization was calculated by computing the area under the vocalization curve on an inkwriting oscilloscope. The pre-drug vocalization magnitude was determined by means 
of the average of 5 vocalization areas. The post-drug vocalization magnitude was calculated by the average vocalization of all measurements made on each animal over the whole post-drug period. Drug effects were determined, by comparing the vehicle- and drug-administration magnitude of vocalization. The dose which produced 50\% reduction (ED50 values) was determined by the probit analysis based on 3 logarithmically spaced doses per drug. Eighteen rats were uesd in each experimental group for determining the ED50 values.

\section{Drugs}

The drugs uesd were morphine hydrochloride (Shionogi), indomethacin (Sigma), diclofenac sodium (Fujisawa), aminopyrine (Sigma) and acetaminophen (Sigma). Morphine, diclofenac, aminopyrine and acetaminophen were dissolved in saline. Aminopyrine at $200 \mathrm{mg} / \mathrm{kg}$, acetaminophen at $400 \mathrm{mg} / \mathrm{kg}$ and $400 \mu \mathrm{g} / 10 \mu \mathrm{l}$, and diclofenac at $80 \mu \mathrm{g} / 10 \mu \mathrm{l}$ were administered as fine homogenous suspensions. Indomethacin was dissolved in $0.1 \mathrm{M}$ Tris buffer with a $\mathrm{pH}$ of 7.9. All drugs were dissolved just before using. All other solvents for extraction and thin layer chromatography were reagent grade and were used without further purification.

\section{Results}

Effects of analgesic drugs given by systemic and icv administrations on the vocalization response in normal and adjuvant arthritic rats: Indomethacin given systemically (2 mg/kg, p.o.) or icv (3 $\mu \mathrm{g} / \mathrm{rat}$ ) markedly inhibited the vocalization response in adjuvant arthritic rats (Fig. 1). As shown in Fig. 2, typical analgesic drugs such as morphine (narcotic analgesic drug), indomethacin (acidic NSAIDs) and acetaminophen (nonacidic NSAIDs) produced dosedependent inhibitory effects on the vocalization response in adjuvant arthritic and normal rats, but a larger dose of these drugs was required in normal rats.

The ED50 values of the drugs used in this experiment are shown in Table 1, giving a comparison of the adjuvant arthritic and normal rats. The ratio of each drug's ED50 value (ED50 values in normal rats/ED50 values in adjuvant arthritic rats) was calculated. The ratios of the normal rats to adjuvant arthritic rats of morphine, aminopyrine and acetaminophen given systemically, and/or icv were between 1 and 5 . Those of indomethacin and diclofenac given by both routes were between 13 and 38 (Fig. 3).

Effects of simultaneous systemic and icv
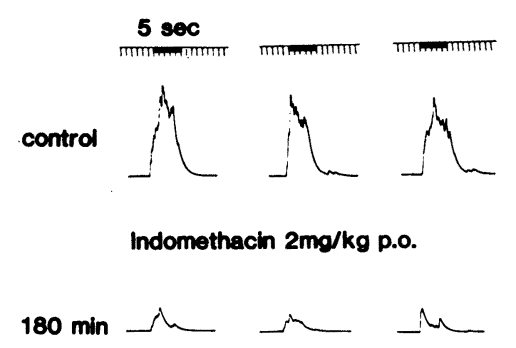

$300 \mathrm{~min}$

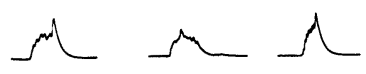

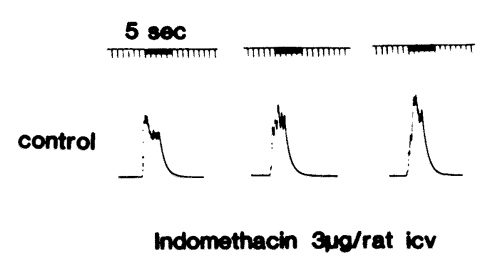
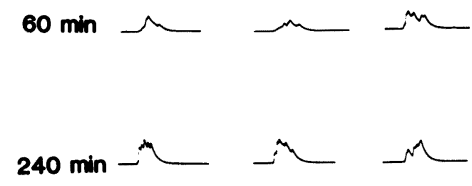

Fig. 1. Effect of indomethacin given systemically (2 mg/kg, p.o.) or icv (3 $\mu \mathrm{g} / \mathrm{rat})$ on the vocalization response in adjuvant arthritic rats. The vocalization response was detected with a microphone, passed through an integrator connected to a biophysical amplifier, low cut filter and recorded on an ink-writing oscilloscope. A low cut filter was used to exclude frequencies below $530 \mathrm{~Hz}$ since the frequency of vocalization from rats was about $2000 \mathrm{~Hz}$. The scale of the ordinate represents the integrated values of vocalization wave detected with a microphone. 

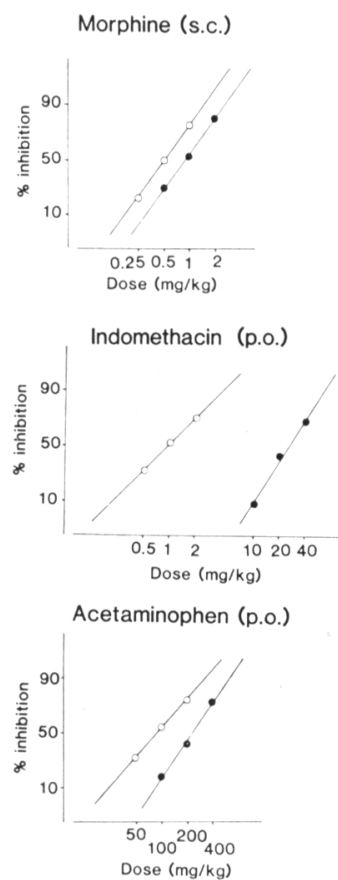

Fig. 2. Dose response curves of inhibitory effects of morphine, indomethacin and acetaminophen given systemically or icv in adjuvant arthritic rats $(-\mathrm{O}-)$ and normal rats (-O-). Each point represents the means of 6 animals. administrations of analgesic drugs in adjuvant arthritic and normal rats: In this experiment, the calculated $25 \%$ effective doses of 5 analgesic drugs were used for the systemic and icv administrations. The experimental design consisted of 4 groups: $A=$ vehicle (icv) +vehicle (systemic); $B=$ vehicle (icv) + drug (systemic); $\quad C=$ drug (icv) + vehicle (systemic) and $\mathrm{D}=$ drug (icv) +drug (systemic). In normal rats, the dose of 5

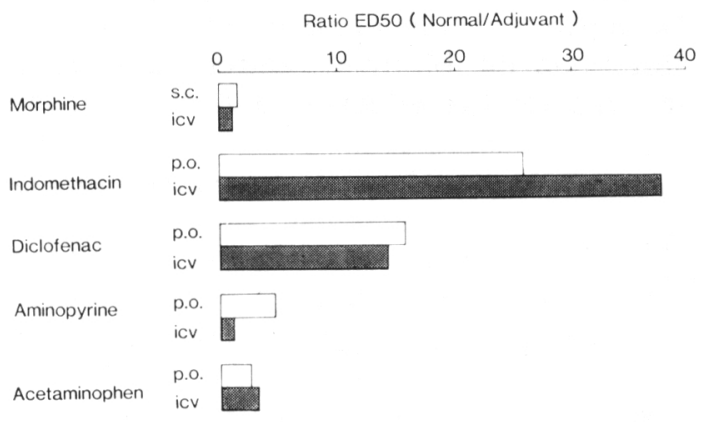

Fig. 3. The difference between adjuvant arthritic rats and normal rats in the pattern of analgesic potency. The ratio of each drug's ED50 value: ED50 values of normal rats/ED50 values of adjuvant arthritic rats.

Table 1. The $50 \%$ inhibitory doses of various analgesic drugs on the vocalization response in adjuvant arthritic rats and normal rats

Systemic administration

\begin{tabular}{|c|c|c|c|}
\hline Test drugs & Route & $\begin{array}{l}\text { Adjuvant arthritic rats } \\
\text { ED50 ( } 95 \% \text { C.L.) } \mathrm{mg} / \mathrm{kg}\end{array}$ & $\begin{array}{c}\text { Normal rats } \\
\text { ED50 (95\% C.L.) } \mathrm{mg} / \mathrm{kg}\end{array}$ \\
\hline Morphine & S.c. & $0.52 \quad(0.24-1.32)$ & $0.88(0.50-1.56)$ \\
\hline Indomethacin & p.o. & $0.91 \quad(0.45-1.91)$ & $(12.1-44.9)$ \\
\hline Diclofenac & p.o & $4.1 \quad(2.1-7.9)$ & $(28.8-146.0)$ \\
\hline Aminopyrine & p.o & $21.9 \quad(10.9-44.6)$ & $(61.3-191.6)$ \\
\hline Acetaminophen & p.o & $88.1 \quad(45.0-172.6)$ & $(122.5-427.0)$ \\
\hline \multicolumn{4}{|c|}{ Intracerebroventricular administration } \\
\hline \multirow{2}{*}{\multicolumn{2}{|c|}{ Test drugs }} & Adjuvant arthritic rats & Normal rats \\
\hline & & ED50 (95\% C.L.) $\mu \mathrm{g} / \mathrm{rat}$ & ED50 (95\% C.L.) $\mu \mathrm{g} / \mathrm{rat}$ \\
\hline Morphine & & $0.50 \quad\left(\begin{array}{ll}0.30- & 0.84)\end{array}\right.$ & $(0.27-1.38)$ \\
\hline Indomethacin & & $1.31(0.75-2.45)$ & $(29.3-83.8)$ \\
\hline Diclofenac & & $6.8 \quad(2.3-24.4)$ & $(44.2-180.9)$ \\
\hline Aminopyrine & & $(13.2-63.4)$ & $(15.9-58.5)$ \\
\hline Acetaminophen & & $(26.9-146.4)$ & $(64.6-654.6)$ \\
\hline
\end{tabular}

Eighteen animals were used in each experimental group for determining the ED50 values. C.L.: confidence limits. 
drugs for systemic and icv administration were as follows: morphine, $0.5 \mathrm{mg} / \mathrm{kg}$ s.c. and $0.25 \mu \mathrm{g} / \mathrm{rat}$, respectively; indomethacin, 15 $\mathrm{mg} / \mathrm{kg}$ p.o. and $25 \mu \mathrm{g} / \mathrm{rat}$; diclofenac, 35 $\mathrm{mg} / \mathrm{kg}$ p.o. and $45 \mu \mathrm{g} / \mathrm{rat}$; aminopyrine, $70 \mathrm{mg} / \mathrm{kg}$ p.o. and $16 \mu \mathrm{g} / \mathrm{rat}$; acetaminophen, $140 \mathrm{mg} / \mathrm{kg}$ p.o. and $70 \mu \mathrm{g} / \mathrm{r}$ at. For adjuvant arthritic rats, they were as follows: morphine, $0.3 \mathrm{mg} / \mathrm{kg}$ s.c. and $0.3 \mu \mathrm{g} / \mathrm{rat}$, respectively; indomethacin, $0.45 \mathrm{mg} / \mathrm{kg}$ p.o. and $0.8 \mu \mathrm{g} / \mathrm{rat}$; diclofenac, $2 \mathrm{mg} / \mathrm{kg}$ p.o. and $3 \mu \mathrm{g} / \mathrm{rat}$; aminopyrine, $11 \mathrm{mg} / \mathrm{kg}$ p.o. and $14 \mu \mathrm{g} / \mathrm{rat}$; acetaminophen, $45 \mathrm{mg} / \mathrm{kg}$ p.o. and $28 \mu \mathrm{g} / \mathrm{rat}$. Morphine and acetaminophen showed additive effects in both types of rats.

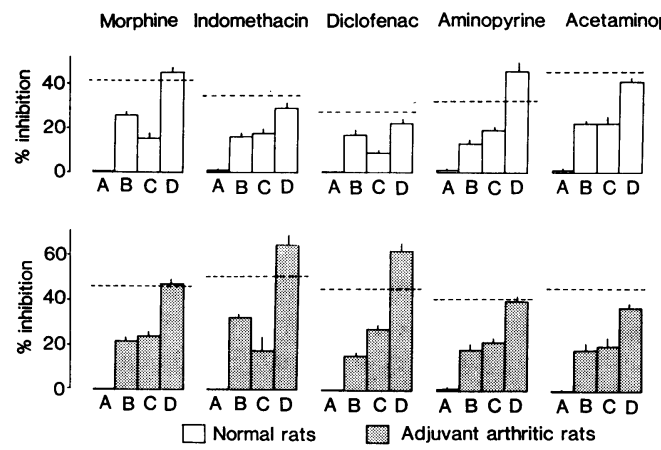

Fig. 4. Effect of combined icv and systemic administration of analgesic drugs in normal rats (upper) and adjuvant arthritic rats (lower). A: vehicle (icv)+vehicle (systemic), B: vehicle (icv)+ drug (systemic), C: drug (icv) + vehicle (systemic), D: drug (icv)+drug (systemic). The doses given together or by either route were the calculated $25 \%$ effective dose of each drug. See the text for the experimental design. The summation of icv and systemic effects is indicated by the dotted line. Each group consisted of 6 animals. The vertical bar represents S.E.
Indomethacin and diclofenac showed additive effects in normal rats and showed a synergistic effect in adjuvant arthritic rats. Aminopyrine showed a synergistic effect in normal rats and showed an additive effect in adjuvant arthritic rats (Fig. 4).

The brain and serum levels of nonmetabolized indomethacin and aminopyrine after systemic administrations in normal and adjuvant arthritic rats: In these experiments, the oral dose and sampling time were used for the highest dose of each drug and peak time of the effects using the analgesic test, respectively.

The results in Table 2 showed that nonmetabolized indomethacin and aminopyrine existed in the brain and serum. In adjuvant arthritic rats, the concentration of these drugs in the brain and serum were higher than in normal rats.

When indomethacin was orally administered in adjuvant arthritic rats, the nonmetabolized indomethacin was $0.8 \mu \mathrm{g} / \mathrm{brain}$, and the ED50 values of icv administered indomethacin was $1.31 \mu \mathrm{g} / \mathrm{rat}$. The effective dose of the icv administration was roughly the same level as the brain concentration of the systemic administration. In the normal rats, the dose of the icv administration was 17 times higher than the brain level.

The brain level of the non-metabolized aminopyrine in adjuvant arthritic rats (50 $\mathrm{mg} / \mathrm{kg}$ ) and normal rats $(200 \mathrm{mg} / \mathrm{kg}$ ) were of the same order of 6-7 $\mu \mathrm{g} / \mathrm{brain}$ in both types of rats. The effective dose of the icv administration of aminopyrine was 4-4.5 times higher than the brain concentration of the non-metabolized aminopyrine in both types of rats.

Table 2. Brain and serum levels of non-metabolized indomethacin and aminopyrine in normal rats and adjuvant arthritic rats

\begin{tabular}{|c|c|c|c|c|c|}
\hline \multirow{2}{*}{ Drugs } & \multirow{2}{*}{ Animals } & \multirow{2}{*}{$\begin{array}{c}\text { Dose } \\
\text { (mg/kg, p.o.) }\end{array}$} & \multirow{2}{*}{$\begin{array}{l}\text { Time } \\
\text { (hr) }\end{array}$} & \multicolumn{2}{|c|}{ Concentration } \\
\hline & & & & Brain $(\mu \mathrm{g} /$ brain $)$ & Serum $(\mu \mathrm{g} / \mathrm{ml})$ \\
\hline \multirow[t]{2}{*}{ Indomethacin } & NR & 40 & 1 & $2.8 \pm 1.5$ & $50.9 \pm 8.8$ \\
\hline & AAR & 2 & 3 & $0.8 \pm 0.5$ & $10.0 \pm 4.1$ \\
\hline \multirow[t]{2}{*}{ Aminopyrine } & NR & 200 & 0.5 & $6.6 \pm 2.9$ & $6.6 \pm 1.8$ \\
\hline & AAR & 50 & 2 & $7.3 \pm 3.5$ & $3.1 \pm 1.7$ \\
\hline
\end{tabular}

Each value represents the mean \pm S.E. of 6 animals. NR: normal rats. AAR: adjuvant arthritic rats. 


\section{Discussion}

Adjuvant arthritic rats have been widely used to evaluate the analgesic potency as an experimental model of chronic inflammatory pain $(11,14-18)$.

In our previous study (11), the vocalization response evoked by a conditioning electrical stimulation for adjuvant arthritic rats was useful for evaluation of analgesic drugs. We have observed that adjuvant arthritic rats exhibited a lower pain threshold than normal rats. Despite the high sensitivity of adjuvant arthritic rats to pain, the vocalization response induced by electrical stimulation was inhibited by a wide variety of analgesic drugs, whereas antipsychotic, antianxiety, antidepressant, anticholinergic, antihistaminic, antiserotonergic and centrally acting muscle relaxants were all inactive.

In the present study, icv administrations of acidic NSAIDs, indomethacin and diclofenac, produced a strong analgesic action as well as systemic administrations in adjuvant arthritic rats, but those drugs given by systemic and/or icv administrations produced a mild analgesic action in normal rats. Morphine, aminopyrine and acetaminophen given by both routes had roughly the same analgesic effect in both types of rats. It was well established that the analgesic action of acidic NSAIDs has only been shown in the presence of inflammation, while narcotic analgesic drugs and nonacidic NSAIDs increased the pain threshold for both inflamed and normal tissue $(19,20)$. The results from the present data for the systemic and icv administrations of drugs support this concept.

Our experiments clearly showed a central analgesic action of acidic NSAIDs regarding the hyperalgesia induced by adjuvant. With simultaneous systemically and icv administered indomethacin and/or diclofenac, the normal rats showed only an additive effect, but adjuvant arthritic rats showed a synergistic effect rather than a simple addition. Only the additive effect was observed with aminopyrine and acetaminophen in adjuvant arthritic rats. It is probably because its central and systemic effects were usually of the same order as the analgesic effect in this model. Our experiments did not allow us to evaluate the relative contribution of the central action to the overall analgesia induced by a systemic administration of acidic NSAIDs. Central analgesic action might be relevant to those inflammatory conditions in which there is synergism, rather than a simple addition, between the central and peripheral effects. In such a case, a strong analgesia would be produced by a small dose of acidic NSAIDs by both routes.

According to Ferreira et al. (7), the concept of inflammatory pain, hyperalgesia, has two components resulting from prostaglandin release: a peripheral one, due to the local sensitizing action of pain receptors and a central one, possibility due to the participation of the central pain circuits. The NSAIDs may exert an analgesic action by preventing the hyperalgesia induced by a peripheral and/or central release of prostaglandins.

However, the study was carried out without discrimination between acidic NSAIDs and nonacidic NSAIDs. It is generally accepted that acidic NSAIDs inhibit the prostaglandins biosynthesis, and prostaglandins are involved as mediators of the inflammatory pain. Nonacidic NSAIDs have little or no effect on the prostaglandins biosynthesis $(8,9)$. In addition, it was reported that prostaglandins were released into the CNS following peripheral nerve stimulation $(21,22)$, and they had an excitatory effect on the dorsal horn interneurones (23).

It would be, therefore, reasonable to assume that hyperalgesia induced by adjuvant may be related to the prostaglandins biosynthesis, and analgesic action of acidic NSAIDs is mainly due to the inhibition of prostaglandins biosynthesis at the central level as well as the peripheral level. Unlike acidic NSAIDs, the analgesic action of nonacidic NSAIDs is partly due to the results of the inhibition of the prostaglandins biosynthesis, but may be due to some other unknown mechanism.

The brain and serum levels of nonmetabolized indomethacin and aminopyrine were-measured after the systemic administrations of this drug to normal and adjuvant arthritic rats. The non-metabolized indomethacin and aminopyrine existed in the 
brain and serum. It has been known that NSAIDs do not penetrate the blood brain barrier to any great extent. Thus indomethacin and acetaminophen were in a much lower concentration in the brain than in other organs $(24,25)$. The brain and serum levels of these drugs in adjuvant arthritic rats were higher than in normal rats. In regards to this observation, Sofia (26) reported that the liver microsomal enzyme activity related to NSAIDs metabolism is markedly reduced in adjuvant arthritic rats. The effective dose of the icv administration of indomethacin was the same as the brain concentration of nonmetabolized indomethacin when systemically administered. In normal rats, the effective dose of indomethacin administered icv and the brain concentration of indomethacin administered systemically showed conflicting results. These results supported the idea that the strong analgesic action of indomethacin in adjuvant arthritic rats may be related to the generation of prostaglandins in the CNS.

Collier and Roy (27) postulated the involvement of prostaglandin released in the CNS in the mechanism of morphine analgesia. They proposed that morphine analgesia resulted from a blockade of the increase of cyclic AMP which could be induced by an endogenous release of the prostaglandins. We believe that acidic NSAIDs and morphine have different modes of action. Morphine has a depressor effect on the central mechanisms involved in nociception, while acidic NSAIDs, by inhibiting the synthesis of prostaglandins, prevent the central and peripheral sensitization of these mechanisms.

Our results seem to contradict those of Lim et al. (3) who were not able to show the central effect of acidic NSAIDs. However in their model, there was no inflammation. From results in the present study, it is suggested that the central analgesic action of acidic NSAIDs such as indomethacin and diclofenac is clearly detectable in the presence of chronic inflammation.

Acknowledgement: We would like to thank Dr. K. Kyogoku for analyzing the indomethacin and aminopyrine in the brain and serum.

\section{References}

1 Guzman, F., Braun, C. and Lim, R.K.S.: Visceral pain and the pseudoaffective response to intraarterial injection of bradykinin and other algesic agents. Arch. Int. Pharmacodyn. Ther. 136, 353-384 (1962)

2 Guzman, F., Braun, C., Lim, R.K.S., Potter, G.D. and Rodgers, D.W.: Narcotic and non-narcotic analgesics which block visceral pain evoked by intra-arterial injection of bradykinin and other algesic agents. Arch. Int. Pharmacodyn. Ther. 149, 571-588 (1964)

3 Lim, R.K.S., Guzman, F., Rodgers, D.W., Goto, K., Braun, C., Dickerson, G.D. and Engle, R.J.: Site of action of narcotic and non-narcotic analgesics determined by blocking bradykinin evoked visceral pain. Arch. Int. Pharmacodyn. Ther. 152, 25-58 (1964)

4 Ferreira, S.H.: Prostaglandins, aspirin-like drugs and analgesia. Nature (New Biol.) 240, 200-203 (1972)

5 Vane, J.R.: Inhibition of prostaglandin synthesis as a mechanism of action for aspirin-like drugs. Nature (New Biol.) 231, 232-235 (1971)

6 Ferreira, S.H., Moncada, S. and Vane, J.R.: Prostaglandins and the mechanism of analgesia produced by aspirin-like drugs. Br. J. Pharmacol. 49, 86-97 (1973)

7 Ferreira, S.H., Lorenzetti, B.B. and Correa, F.M.A.: Central arid peripheral antialgesic action of aspirin-like drugs. Eur. J. Pharmacol. 53, 3948 (1978)

8 Fitzpatrick, F.A. and Wynalda, M.A.: In vivo suppression of prostaglandin biosynthesis by non-steroidal anti-inflammatory agents. Prostaglandins 12, 1039-1051 (1976)

9 Abdel-Halim, M.S., Sjöquist, B. and Änggảrd, E.: Inhibition of prostaglandin synthesis in rat brain. Acta Pharmacol. Toxicol. 43, 266-272 (1978)

10 Chen, A.C.N. and Chapman, C.R.: Aspirin analgesia evaluated by event-related potentials in man: Possible central action in brain. Exp. Brain Res. 39, 359-364 (1980)

11 Okuyama, S. and Aihara, H.: Inhibition of electrically-induced vocalization in adjuvant arthritic rats as a novel method for evaluating analgesic drugs. Japan. J. Pharmacol. 34, 67-77 (1984)

12 Côrrea, F.M.A. and Graeff, F.G.: Central mechanism of the hypertensive action of intraventricular bradykinin in the unanaesthetized rats. Neuropharmacology $13,65-72$ (1974)

13 Pellegrino, L.J. and Cushman, A.J.: A Stereotaxic Atlas of the Rat Brain. Appleton-CenturyCrofts, New York (1967)

14 Kuzuna, S. and Kawai, K.: Evaluation of analgesic agents in rats with adjuvant arthritis. Chem. 
Pharm. Bull. (Tokyo) 23, 1184-1191 (1975)

15 Winter, C.A., Kling, P.J., Tocco, D.J. and Tanabe, K.: Analgesic activity of diflunisal MK647: 5-(2,4-difluorophenyl) salicylic acid in rats with hyperalgesia induced by Freund's adjuvant. J. Pharmacol. Exp. Ther. 211, 678-685 (1979)

16 Capetola, R.J., Shriver, D.A. and Rosenthale, M.E.: Suprofen, a new peripheral analgesics. J. Pharmacol. Exp. Ther. 214, 16-23 (1980)

17 Pircio, A.W., Fedele, C.T. and Bierwagen, M.E.: A new method for the evaluation of analgesic activity using adjuvant induced arthritis in the rat. Eur. J. Pharmacol. 31, 207-215 (1975)

18 Costa, M.C., Sutter, P., Gybels, J. and Hees, J.V.: Adjuvant-induced arthritis in rats: A possible animal model of chronic pain. Pain 10,173185 (1981)

19 Randall, L.O. and Selitto, J.J.: A method for the measurement of analgesic activity on inflamed tissue. Arch. Int. Pharmacodyn. Ther. 111, 409-419 (1957)

20 Winter, C.A. and Flataker, L.: Reaction thresholds to pressure in edematcus hindpaws and responses to analgesic drugs. J. Pharmacol. Exp. Ther. 150, 165-171 (1965)

21 Ramwell, P.W. and Shaw, J.E.: Spontaneous and evoked release of prostaglandins from cerebral cortex of anaesthetized cats. Am. J. Physiol. 211, 125-134 (1966)

22 Ramwell, P.W., Shaw, J.E. and Jessup, R.: Spontaneous and evoked release of prostaglandins from frog spinal cord. Am. J. Physiol. 211, 998-1004 (1966)

23 Coceani, F. and Viti, A.: Responses of spinal neurons to iontophoretically applied prostaglandin $E_{1}$ in the frog. Can. J. Physiol. Pharmacol. 53, 273-284 (1975)

24 Hucker, H.B., Zacchei, A.G., Cox, S.V., Brodie, D.A. and Cantwell, N.H.R.: Studies on the absorption, distribution and excretion of indomethacin in various species. J. Pharm. Exp. Ther. 153, 237-249 (1961)

25 Davison, C., Guy, J.L., Levitt, M. and Smith, P.K.: The distribution of certain non-narcotic analgesic agents in the CNS of several species. J. Pharm. Exp. Ther. 134, 176-183 (1961)

26 Sofia, D.A.: Alteration of hepatic microsomal enzyme systems and the lethal action of nonsteroidal anti-inflammatory drugs in acute and chronic model of inflammation. Agents Actions 7, 289-297 (1977)

27 Collier, H.O.J. and Roy, C.A.: Inhibition of $E$ prostaglandin sensitive adenyl cyclase as the mechanism of morphine analgesia. Prostaglandins 7, 361-376 (1974) 